GENOME METHODS

\title{
High-Throughput Microsatellite Analysis Using Fluorescent dUTPs for High-Resolution Genetic Mapping of the Mouse Genome
}

\author{
Michael Rhodes, ${ }^{1}$ Andrew Dearlove, ${ }^{1}$ Richard Straw, ${ }^{1}$ Supem Fernando, \\ Andy Evans, ${ }^{1}$ Marc Greener, ${ }^{1}$ Tregaye Lacey, ${ }^{1}$ Maria Kelly, ${ }^{1}$ \\ Keith Gibson, ${ }^{1}$ Steve D.M. Brown, ${ }^{2,3}$ and Chris Mundy ${ }^{1}$
}

\author{
${ }^{1}$ MRC Human Genome Mapping Project Resource Centre, Hinxton, Cambridge CB10 1SB, UK; ${ }^{2}$ MRC \\ Mouse Genome Centre, Harwell, Oxfordshire OX11 ORD, UK
}

\begin{abstract}
The use of fluorescent end-labeled primers has proved successful for rapid, semiautomated genotyping of microsatellite loci. However, custom synthesis is expensive and costs can be prohibitive when a wide range of markers is to be analyzed for only a few genotypings. This particularly applies to high-resolution genetic mapping in the mouse either in the construction of global maps or in the production of local high-resolution genetic maps for positional cloning. We demonstrate here the use of fluorescent dUTPs for cost-effective, high-throughput microsatellite genotyping in the mouse. This alternative to the use of fluorescent end-labeled primers for semiautomated genotyping is potentially applicable to the construction of linkage maps in other species.
\end{abstract}

The use of fluorescent $5^{\prime}$ end-labeled primers for rapid, semiautomated genotyping of human microsatellite loci has been successfully proven (Reed et al. 1994) and subsequently employed for genomewide scanning for disease loci (Davies et al. 1994). However, there are still a number of applications and situations in which this technology cannot readily be applied. For example, custom synthesis is expensive and the cost can be prohibitive when a wide range of markers is required for only a few genotypings. Nevertheless, the use of fluorescently labeled PCR products is at a premium because such PCR products can be rapidly and routinely genotyped using automated detection systems and genotyping software that has many advantages over conventional autoradiographic detection systems (Reed et al. 1994).

Over 6000 microsatellite markers have been developed for the mouse genome and mapped to intermediate resolution (Dietrich et al. 1996). However, the bulk of microsatellite marker genotyping in the mouse to date has employed conventional agarose- or acrylamide-based gel detection systems (Dietrich et al. 1992; Breen et al. 1994; Rowe et al. 1994). Limited sets of fluorescent end-labeled prim-

${ }^{3}$ Corresponding author.

E-MAlL s.brown@har.mrc.ac.uk; FAX 01235834776. ers are available commercially for genome scanning in the mouse. Nevertheless, constraints on the use of fluorescently labeled PCR products apply particularly to work on the genetic mapping of the mouse genome. Two practical applications can be envisaged for mouse genome mapping where the use of a more cost-effective method for automated fluorescent genotyping would pay dividends; both concern high-resolution genetic mapping.

The first application is high-resolution genetic analysis of a specific chromosome region-for example, a region containing a mouse mutation. For positional cloning of a mouse mutation the first step is often to set up a large genetic cross segregating the mutation of interest (Copeland et al. 1993; Brown 1994; Zhang et al. 1994; Dietrich et al. 1995; Gibson et al. 1995). The mutation may already be localized to a relatively small chromosome region bounded by two flanking markers. Analysis of all of the progeny from the large genetic cross with the flanking markers identifies an informative panel of mice recombinant between the flanking markers. This recombinant panel can be used for the highresolution genetic mapping of the mutation of interest by the analysis of all markers, particularly microsatellite markers, from within this region. The initial localization of a new mutation in the genome may be carried out using existing panels of available 


\section{RHODES ET AL.}

fluorescent end-labeled primers. However, alternative approaches must be employed for the highresolution genetic mapping of the mutation that uses all available microsatellite markers from the relevant region, few of which will be available as fluorescent end-labeled primers.

The second major application is the construction of genome-wide high-resolution genetic maps incorporating the bulk of microsatellite markers. Such genome-wide high resolution maps will have an important role in aiding the construction of complete, robust, physical maps of the mouse genome (Brown 1994; Dietrich et al. 1996). For example, the European Collaborative Interspecific Backcross (EUCIB) program employs a large interspecific backcross between C57BL/6 and Mus spretus for high resolution genome-wide genetic mapping (Breen et al. 1994). From this backcross 982 progeny were produced and they have been analyzed for a variety of primary and secondary anchor markers across the genome. The anchor marker analysis identifies panels of recombinant mice (as small as 36) from every chromosome region that can be used for efficient high-resolution mapping of microsatellite markers. The EUCIB backcross provides a genetic mapping resource at $0.3-\mathrm{cM}$ resolution, which corresponds to $\sim 0.5 \mathrm{Mb}$ in the mouse genome. This high-resolution genetic mapping program clearly requires extensive genotyping with thousands of microsatellite markers, few of which are available as fluorescent end-labeled primers.

In order to speed the process of high-resolution genetic mapping in the mouse genome, we have sought to devise methods for high-throughput automated genotyping that are not dependent upon the availability of fluorescent end-labeled primers. We report here the use of fluorescent dUTPs ([F]dUTPs) for cost-effective, high-throughput microsatellite genotyping in the mouse.

\section{RESULTS}

\section{Development of Methodology-Incorporation of [F]dUTPs into PCR Products}

Three [F]dUTPs are currently available: R110, R6G, and TAMRA (see Methods). We sought to explore their potential to label fluorescently microsatellite PCR products and their utility for mouse microsatellite genotyping. We have employed standard PCR reaction conditions for all microsatellites analyzed in order to ensure high-throughput with a reasonable degree of success (see below) and have concen- trated on optimizing the incorporation of [F]dUTPs. It was found that simple addition of [F]dUTPs provided sufficient incorporation into the PCR products without altering previously optimized reaction conditions. The ratio of [F]dUTPs to dTTP was found to be critical to achieve the necessary incorporation of [F]dUTPs for reliable detection by ABI $377 \mathrm{~s}$ or ABI 373As (i.e., a signal-to-noise ratio exceeding 5). Generally, in arbitrary fluorescence units, noise was around 5 units and signal varied from 80 to 600 units depending on the marker tested. The appropriate concentrations of [F]dUTPs in the PCR reactions along with the [F]dUTP to dTTP ratio is given in Table 1.

\section{Development of Methodology-Genotyping}

In the majority of mouse genetic crosses employing inbred or relatively homogeneous strains, only two parental microsatellite alleles are segregating (see also below). [F]dUTP analysis of parental DNAs is first carried out in order to determine parental allele sizes for the subsequent allele calling of backcross progeny (see Methods). [F]dUTP PCR products of parental or backcross DNAs are loaded onto either an ABI 377 or ABI 373 and analyzed via Genescan Analysis software version 2.02 and Genotyper version 1.1.1 (see Methods). Figure 1A provides an example of output traces from a single gel lane employing all three [F]dUTPs and a total of eight microsatellites loaded and scored for one backcross progeny mouse derived from EUCIB C57BL/ $6 \times M$. spretus interspecific backcross. Figure 1 details the parental allele sizes [(LB) C57BL/6; (LS) M. spretus] segregating and scored for each marker in the example shown (see also legend to Fig. 1A). Three different microsatellite markers were analyzed for both the R110 (blue) and R6G (green) [F]dUTPs whereas for the third [F]dUTP (TAMRA, yellow) two microsatellites were loaded. The stutter characteristic of microsatellites can be seen clearly (Fig. 1B) and can

\section{Table 1. PCR Conditions for Use of [F]dUTPs}

\begin{tabular}{lll}
\hline [F]dUTP & $\begin{array}{l}\text { Final concentration } \\
\text { in PCR reaction }\end{array}$ & $\begin{array}{l}\text { Ratio of dUTP } \\
\text { to dTTP }\end{array}$ \\
\hline R110 & $0.5 \mu \mathrm{M}$ & $1: 400$ \\
R6C & $1 \mu \mathrm{M}$ & $1: 200$ \\
TAMRA & $8 \mu \mathrm{M}$ & $1: 25$
\end{tabular}


MICROSATELLITE ANALYSIS USING FLUORESCENI DUTPS

serve as an aid in differentiating real from false peaks. A 1-bp stutter was seen on the majority of markers. The vast majority of mouse microsatellites show large allele size differences, which lends itself to the technique of incorporated [F]dUTPs and for this reason we did not optimize the $\mathrm{PCR}$ reactions to remove the 1-bp stutter. Nevertheless, Figure 1B also demonstrates that sufficient resolution can be achieved to score some microsatellite size variants separated by only $4 \mathrm{bp}$. All microsatellite size variants with $>4$-bp separation could be resolved.

\section{Throughput}

Multipooling of 6-9 samples is possible (see Fig. 1) and has allowed us to achieve a throughput of up to 324 genotypings per gel. Multiplexing of sixfold or more was routinely adopted for the mapping of backcross panels. A higher degree of multipooling would be possible if it were not for the fact that many of the published primers for mouse microsatellite markers amplify products in the 130- to 150-bp range (Dietrich et al. 1996).

The Methodology Is Widely Applicable Across the Available Mouse Microsatellite Resource

In order to demonstrate that this methodology is widely applicable across a large number of mouse microsatellite markers, we have used incorporated [F]dUTPs for the high-resolution mapping of a number of mouse chromosomes. The details and analysis of the high-resolution maps will be published elsewhere and are currently available through the EUCIB World Wide Web site (http://www.hgmp.mrc.ac.uk/

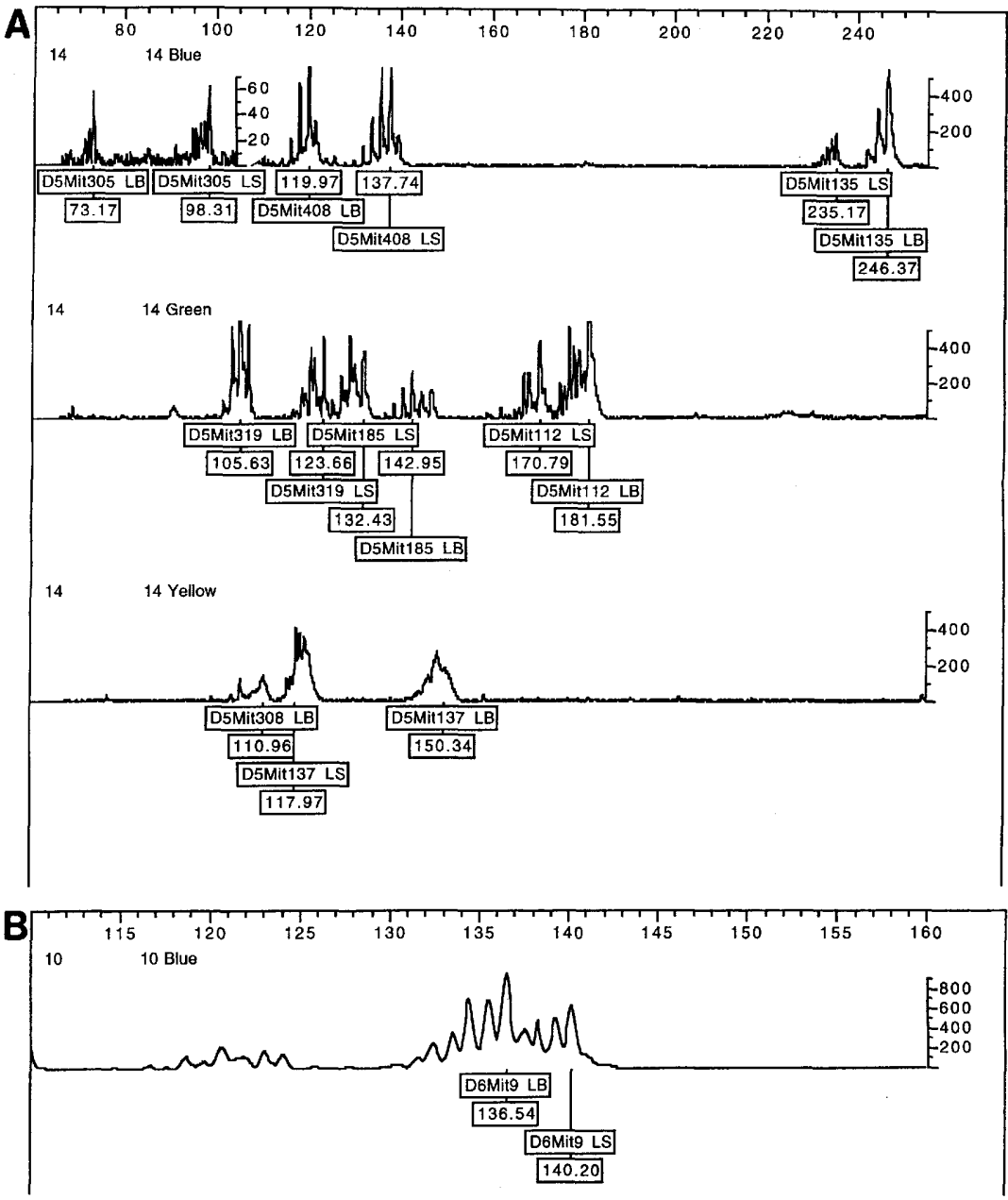

Figure 1 Microsatellite genotyping using [F]dUTPs. Output traces generated using microsatellite genotyping employing [F]dUTPs. Samples were electrophoresed using an $A B I$ Prism 377. DNA fragment sizing was carried out using Genescan (version 2.02) and genotyping using Genotyper (version 1.1.1) (see Methods). Relative fluorescence is indicated on the $y$-axis and Genotyper provides allele sizes to $1 / 100$ th of a base $(x$-axis). (A) Output traces generated from a single lane employing all three [F]dUTPs [(blue) R110; (green) R6G; (yellow) TAMRA] and a total of eight microsatellites (D5Mit305, D5Mit408, D5Mit135, D5Mit319, D5Mit185, D5Mit112, D5Mit308, D5Mit137). Highest peaks that fell within the expected size range as determined for the parental alleles LB (C57BL/ 6) and LS (M. spretus) were selected (see Methods) and are shown. Microsatellite D5Mit308 does not amplify a $M$. spretus allele and is scored by presence or absence in progeny derived by backcrossing to $M$. spretus.

\begin{tabular}{lcc} 
Parental Allele Sizes & LB & \multicolumn{1}{c}{ LS } \\
D5MiT305 & 73 & 98 \\
D5Mit408 & 120 & 138 \\
D5Mit135 & 246 & 235 \\
D5Mit319 & 106 & 123 \\
D5Mit185 & 143 & 132 \\
D5Mit112 & 182 & 171 \\
D5Mit308 & 111 & - \\
D5Mit137 & 150 & 118
\end{tabular}

(B) Output trace indicating the separation of D6Mit9 alleles separated by only 4 bp. Parental allele sizes are LB, 136, and LS, 140. A 1-bp stutter is readily apparent. The highest peaks within the defined size range have been selected. 


\section{RHODES ET AL.}

$\mathrm{MBx} /$ Homepage.html). To indicate the efficacy of the methodology we report the success rate for mapping mouse chromosome 2 using the [F]dUTP methodology.

All the existing mouse chromosome 2 microsatellite markers (Dietrich et al. 1996) were analyzed through the EUCIB backcross using [F]dUTPs bar two markers (D2Mit1 and D2Mit11) that had originally been incorporated in the EUCIB anchor map using more conventional technology (Breen et al. 1994). Following determination of parental allele sizes (C57BL/6 and M. spretus), all variant microsatellites were analyzed through the relevant backcross panels using the [F]dUTP approach. A total of 330 microsatellite markers were placed on the mouse chromosome 2 map using [F]dUTPs. This represents $69.1 \%$ of the available markers (477 excluding the two anchors). Of the markers, 17 (3.6\%) could not be analyzed as they failed to demonstrate a size variant between C57BL/6 and M. spretus. And 130 (27.3\%) of the markers failed to amplify successfully. However, as indicated above, because of the high-throughput requirements of the project, we did not return to optimize each primer pair and it is unlikely that the failure of these primer pairs reflects the use of the [F]dUTP methodology. Indeed, many of those markers that failed using [F]dUTP methodology also failed using more conventional analyses (data not shown), such as ${ }^{35}$ S labeling and enhanced chemiluminescence (ECL) (Vignal et al. 1993). Overall, $71.7 \%$ of mappable primers were added to the mouse chromosome map at first pass. Clearly, [F]dUTPs offered a high success rate for highthroughput genotyping in the mouse.

\section{Cost}

With the use of panels of 36 recombinant mice, we calculate total cost per reaction for [F]dUTPs as $£ 0.52$ (\$0.78), representing around a fourfold saving on the purchase and use of $5^{\prime}$ end-labeled primers.

\section{DISCUSSION}

This work has successfully demonstrated the use of [F]dUTPs as a method for cost-effective genotyping in the mouse. The method is demonstrably applicable for high-throughput genome-wide highresolution genetic mapping as being followed by the EUCIB program. It should also be effective in rapid genetic analysis of microsatellite markers in the high-resolution mapping of specific chromosome regions and the fine genetic localization of muta- tions prior to physical mapping and positional cloning.

The method is reliable as exemplified by the high success rate at first pass in using available mouse microsatellite markers from mouse chromosome 2 . Given the potential multiplexing, this approach offers high throughput-up to 324 genotypes per gel run on an ABI. Depending upon PCR product sizes, this genotyping throughput could readily be increased. However, many available mouse microsatellite primers amplify products of similar size in the 130- to 150-bp range (Dietrich et al. 1996). In any particular genotyping project, the redesign of primers may aid in achieving higher levels of multiplexing and higher throughput.

We expect that the use of [F]dUTPs will be a valuable aid to the mouse mapper in speeding genotyping. Nevertheless, the described methodology is potentially applicable to other species. In a number of mammalian species, for example, the rat (Jacob et al. 1995), the pig (Archibald et al. 1995), and the cow (Barendse et al. 1994), relatively dense microsatellite maps have been generated. Additionally the use of microsatellites has been employed to construct a linkage map of the zebrafish (Postlethwait et al. 1994; Knapik et al. 1996). It may indeed prove cost-effective and useful for human genotyping. This will require that the current limit of resolution $-4 \mathrm{bp}-$ be improved. As indicated above, it will be necessary to further optimize the protocol to reduce the 1-bp stutter characteristic. Overall, the use of [F]dUTPs should be useful for high-resolution genetic mapping in a wide variety of species. Moreover, it may be used for rapid genome-wide scanning in species where end-labeled primer resources are not yet available.

\section{METHODS}

\section{EUCIB Backcross Analysis}

Parental and progeny DNAs from the EUCIB backcross were used for both testing and production phases of highresolution mapping using [F]dUTPs. The production of backcross DNA and the initial anchor map has been described previously (Breen et al. 1994). The primary anchor map identified relatively large panels of recombinant mice $(-200$ on average) in each interanchor interval. Subsequently, a variety of secondary and sometimes tertiary anchors have been analyzed through the recombinant panels established by the primary anchors, thus partitioning the recombinant panels into smaller sets. Recombinant panels of $\sim 36$ animals have been established for every chromosome region. Microsatellites are analyzed through the appropriate recombinant panel DNAs. 


\section{MICROSATELLITE ANALYSIS USING FLUORESCENT DUTPS}

\section{Standard PCR Conditions}

Standard PCR conditions were employed throughout both for normal PCR and for PCR incorporating [F]dUTPs. PCR reactions conditions are: $10 \mathrm{~mm}$ Tris at $\mathrm{pH} 8.0,50 \mathrm{mM} \mathrm{KCl}, 2 \mathrm{mM}$ $\mathrm{MgCl}_{2}, 0.1 \%$ Tween, $0.2 \mathrm{~mm}$ dNTPs, $125 \mathrm{ng}$ of each primer, 1 unit AmpliTaq, $20 \mathrm{ng}$ target DNA, total volume $20 \mu \mathrm{l}$. Recently the reaction volume has been halved with no effect on PCR and a consequent further reduction in costs. Each reaction also contains one of three possible [F]dUTPs (Perkin Elmer, $\mathrm{ABI}$ ) at varying concentrations: R110, $0.5 \mu \mathrm{M}$; R6G, 1 $\mu \mathrm{M}$; TAMRA, $8 \mu \mathrm{M}$. The PCR reactions were cycled on a Perkin Elmer Cetus 9600 thermocycler at $\left(94^{\circ} \mathrm{C}\right.$ for $60 \mathrm{sec}, 60^{\circ} \mathrm{C}$ for $60 \mathrm{sec}, 72^{\circ} \mathrm{C}$ for $30 \mathrm{sec}$ ) for 32 cycles followed by $72^{\circ} \mathrm{C}$ for 7 $\min$.

\section{Sample Preparation Prior to Gel Loading}

The finished reactions are pooled and purified using $500 \mu \mathrm{l}$ of $7.5 \%$ Biorad P10, loaded into Millipore Multiscreen GV plates. Up to $80 \mu \mathrm{l}$ of pooled reactions is spun at $800 \mathrm{~g}$ and the eluent is collected (a typical pooling is a total of eight products in the three fluorophores; see above). The samples are then prepared for loading: $0.125 \mu \mathrm{l}$ of 6-carboxy-X-rhodamine (ROX) 350 (internal standard), $1.375 \mu \mathrm{l}$ of deionized formamide to 50 mM EDTA (5:1), containing blue dextran and $1 \mu$ of sample. Prior to loading the sample is heated at $95^{\circ} \mathrm{C}$ for $2 \mathrm{~min}$.

\section{Gel Running}

The samples are run on an ABI Prism 377 automated gel sequencer. Gels $0.2 \mathrm{~mm}$ thick, $4.25 \%$ acrylamide (19:1 acrylamide to bis) were employed and run at $3 \mathrm{kV}, 45^{\circ} \mathrm{C}$ with a $36-\mathrm{cm}$ well to read corresponding to $140 \mathrm{~min}$ run time for 350 base units.

\section{Genotyping and Semiautomated Allele Calling}

Genotypes of both parental and backcross progeny DNAs are analyzed via Genescan Analysis (ABI) software version 2.02 and Genotyper version 1.1.1 (ABI). Allele analysis is a twostage process. For the first stage a sizing gel containing only parental samples is run. This gel provides parental allele sizes in order (1) to determine appropriate microsatellite pooling schemes and (2) to provide parameters (allele-size range) for autoscoring. DNA fragment sizing was performed using Genescan (version 2.02). Gel tracking was corrected manually and sizing was carried out using the Genescan second order least squares method. The sizing curve derived from ROX 350 standard peaks was checked manually for all lanes. Automated allele calling was carried out using Genotyper (version 1.1.1). Employing the data from the sizing gel the range for each allele is defined. Alleles were selected as the highest peak within the defined range and the presence or absence of parental alleles scored. Data was exported as an ASCII file and entered into the EUCIB MBx database (Breen et al. 1994) using a batch entry program written in Tcl/TK. Automated allele calling was generally only employed for large panels of mice when defining anchor loci through large sets of backcross progeny. Otherwise, for the bulk of the mapping panels employing 36 mice the fragment sizing was carried out as described above but allele calling was carried out manually (us- ing the Genotyper display) followed by manual entry into $M B x$.

\section{ACKNOWLEDGMENTS}

This work was supported by the Medical Research Council, UK.

The publication costs of this article were defrayed in part by payment of page charges. This article must therefore be hereby marked "advertisement" in accordance with 18 USC section 1734 solely to indicate this fact.

\section{REFERENCES}

Archibald, A.L., C.S. Haley, J.F. Brown, S. Couperwhite, H.A. McQueen, D. Nicholson, W. Coppieters, A. van de Weghe, A. Stratil, A.K. Winters, M. Fredholm, N.J. Larsen, V.H. Nielsen, D. Milan, N. Woloszyn, A. Robic, M. Dlaens, J. Riquet, J. Gellin, J.-C. Caritez, G. Burgaud, L. Ollivier, J.-P. Bidanet, M. Vaiman, C. Renard, H. Geldermann, R. Davoli, D. Ruyter, E.J.M. Verstege, M.A.M. Groenen, W. Davies, B. Hoyheim, A. Keiserud, L. Andersson, H. Ellegren, M. Johansson, L. Marklund, J.R. Miller, D.V. Anderson Dear, E. Signer, A.J. Jeffreys, C. Moran, P. le Tissier, Muladno, M.F. Rotschild, C.K. Tiggle, D. Vaske, J. Helm, H.-C. Liu, A. Rahman, T.-P. Yu, R.G. Larson, and C.B. Schmitz. 1995. The PiGMaP consortium linkage map of the pig (Sus scrofa) Mamm. Genome 6: 157-175.

Barendse, W., S.M. Armitage, L.M. Kossarek, A. Shalom, B.W. Kirkpatrick, A.M. Ryan, D. Clayton, L. Li, H.L. Neibergs, N. Zhang, W.M. Grosse, J. Weiss, P. Creighton, R. McCarthy, M. Ron, A.J. Teale, R. Fries, R.A. McGraw, S.S. Moore, M. Georges, M. Soller, J.E. Womack, and D.J.S. Hetzel. 1994. A genetic linkage map of the bovine genome. Nature Genet. 6: 227-235.

Breen, M., L. Deakin, B. Macdonald, S. Miller, R. Sibson, E. Tarttelin, P. Avner, F. Bourgade, J.-L. Guenet, X. Montagutelli, C. Poirier, D. Simon, D. Tailor, M. Bishop, M. Kelly, F. Rysavy, S. Rastan, D. Norris, D. Shepherd, C. Abbott, A. Pilz, S. Hodge, I. Jackson, Y. Boyd, H. Blair, G. Maslen, J.A. Todd, P.W. Reed, J. Stoye, A. Ashworth, L. McCarthy, R. Cox, L. Schalkwyk, H. Lehrach, J. Klose, U. Gangadharan, and S. Brown. 1994. Towards high resolution maps of the mouse and human genomes-A facility for ordering markers to $0.1 \mathrm{cM}$ resolution. Hum. Mol. Genet. 3: $621-627$.

Brown, S.D.M. 1994. Integrating maps of the mouse genome. Curr. Opin. Genet. Dev. 4: 389-394.

Copeland, N.G., N.A. Jenkins, D.J. Gilbert, J.T. Eppig, L.J. Maltais, J.C. Miller, W.F. Dietrich, A. Weaver, S.E. Lincoln, R.G. Steen, L.D. Stein, J.H. Nadeau, and E.S. Lander. 1993. A genetic linkage map of the mouse: Current applications and future prospects. Science 262: 57-66.

Davies, J.L., Y. Kawaguchi, S.T. Bennett, J.B. Copeman, H.J. Cordell, L.E. Pritchard, P.W. Reed, S.C.L. Gough, S.M. Palmer, K.M. Balfour, S.C. Jenkins, B. Rowe, M. Farrall, A.H. Barnett, S.C. Bain, and J.A. Todd. 1994. A genome-wide 


\section{RHODES ET AL.}

search for human type I diabetes susceptibility genes. Nature 371: $130-136$.

Dietrich, W., H. Katz, S.E. Lincoln, H.-S. Shin, J. Friedman, N.C. Dracopoli, and E.S. Lander. 1992. A genetic map of the mouse suitable for typing intraspecific crosses. Genetics 131: $423-447$.

Dietrich, W.F., N.G. Copeland, D.J. Gilbert, J.C. Miller, N.A. Jenkins, and E.S. Lander. 1995. Mapping the mouse genome: Current status and future prospects. Proc. Natl. Acad. Sci. 92: 10849-10853.

Dietrich, W.F., J.C. Miller, R. Steen, M.A. Merchant, D. Damron-Boles, Z. Husain, R. Dredge, M.J. Daly, K.A. Ingalis, T.J. O.Connor, C.A. Evans, M.M. DeAngelis, D.M. Levinson, L. Kruglyak, N. Goodman, N.G. Copeland, N.A. Jenkins, T.L. Hawkins, L. Stein, D.C. Page, and E.S. Lander. 1996. A comprehensive genetic map of the mouse genome. Nature 380: 149-152.

Gibson, F., J. Walsh, P. Mburu, A. Varela, K.A. Brown, M. Antonio, K.W. Beisel, K.P. Steel, and S.D.M. Brown. 1995. A type VII myosin encoded by the mouse deafness gene shaker-1. Nature 374: 62-64.

Jacob, H.J., D.M. Brown, R.K. Bunker, M.J. Daly, V.J. Dzau, A. Goodman, G. Koike, V. Kren, T. Kurtz, A. Lernmark, G. Levan, Y.-P. Mao, A. Petterson, M. Pravenec, J.S. Simon, C. Szpirer, J. Szpirer, M.R. Trolliet, E.S. Winer, and E.S. Lander. 1995. Genetics linkage map of the laboratory rat, Rattus norvegicus. Nature Genet. 9: 63-69.

Knapik, E.W., A. Goodman, O. Scott Atkinson, C.T. Roberts, M. Shiozawa, C.U. Sim, S. Weksler-Zangen, M.R. Trolliet, C. Futrell, B.A. Innes, G. Koike, M.G. McLaughlin, L. Pierre, J.S. Simon, E. Vilallonga, M. Roy, P.-W. Chiang, M.C. Fishman, W. Driever, and H.J. Jacob. 1996. A reference cross DNA panel for zebrafish (Danio rerio) anchored with simple sequence length polymorphisms. Development 123: $451-460$.

Postlethwait, J.H., S.L. Johnson, C.N. Midson, W.S. Talbot, M. Gates, E.W. Ballinger, D. Africa, R. Andrews, T. Carl, J.S. Eisen, S. Horne, C.B. Kimmel, M. Hutchinson, M. Johnson, and A. Rodriguez. 1994. A genetic linkage map for the zebrafish. Science 264: 699-703.

Reed, P.W., J.L. Davies, J.B. Copeman, S.T, Bennett, S.M. Palmer, L.E. Prtichard, S.C.L. Gough, Y. Kawaguchi, H.J. Cordell, K.M. Balfour, S.C. Jenkins, E.E. Powell, A. Vignal, and J.A. Todd. 1994. Chromosome-specific sets for fluorescence-based, semi-automated genome mapping. Nature Genet. 7: 390-395.

Rowe, L.B., J.H. Nadeau, R. Turener, W.N. Frankel, V.A. Letts, J.T. Eppig, M.S.H. Ko, S.J. Thurston, and E.H. Birkenmeier. 1994. Maps from two interspecific backcross DNA panels available as a community genetic mapping resource. Mamm. Genome 5: 253-274.

Vignal, A., G. Gyapay, J. Hazan, S. Nguyen, C. Dupreaz, N. Cheron, N. Becuwe, M. Tranchant, and J. Weissenbach. 1993. Nonradioactive multiplex procedure for genotyping of microsatellite markers. In Methods in molecular genetics (ed. Kenneth W. Adolph), Vol. 1, pp. 211-221. Academic Press, San Diego, CA.

Zhang, Y., R. Proenca, M. Maffel, M. Barone, L. Leopold, and J.M. Friedman. 1994. Positional cloning of the mouse obese gene and its human homologue. Nature 372: 425-431.

Received July 12, 1996; accepted in revised form November 12, 1996. 


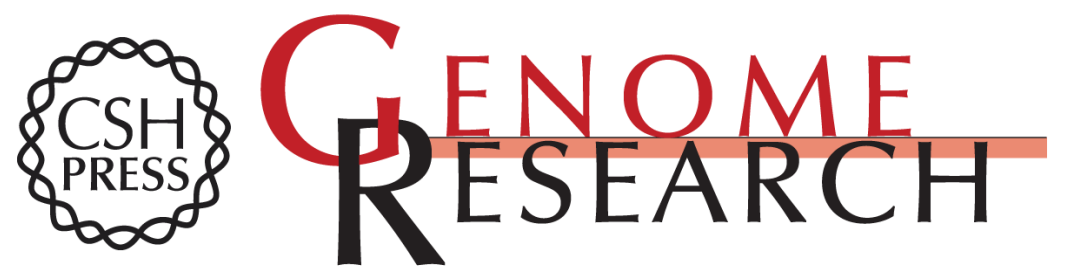

\section{High-throughput microsatellite analysis using fluorescent dUTPs for high-resolution genetic mapping of the mouse genome.}

M Rhodes, A Dearlove, R Straw, et al.

Genome Res. 1997 7: 81-86

Access the most recent version at doi:10.1101/gr.7.1.81

References This article cites 16 articles, 5 of which can be accessed free at:

http://genome.cshlp.org/content/7/1/81.full.html\#ref-list-1

\section{License}

Email Alerting Receive free email alerts when new articles cite this article - sign up in the box at the Service top right corner of the article or click here.

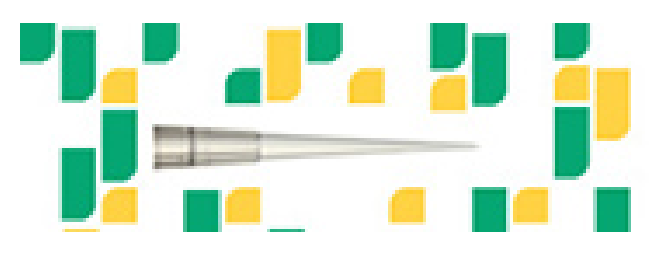

To subscribe to Genome Research go to: https://genome.cshlp.org/subscriptions 